\title{
Pengukuran Mutu Website Akademi Komunitas Negeri Pacitan Menggunakan Metode Webqual
}

\author{
Galih Permadi ${ }^{1}$, Agus Prianggono ${ }^{2)}$ \\ 1) 2) Prodi Pemeliharaan Komputer dan Jaringan AKN Pacitan \\ 1) 2) Jl. Walanda Maramis No. 4A Pacitan \\ 1) galih@aknpacitan.ac.id, ${ }^{2)}$ agus@aknpacitan.ac.id
}

\begin{abstract}
Abstrak
Perkembangan dunia digital terutama pada portal website semakin meningkatkan peranan website bagi dunia informasi. Website merupakan salah satu media informasi yang sangat efisien, cepat, akurat dan tepat. Kita ketahui bahwa hampir semua instansi pemerintahan, perusahaan, perkantorani, universitas, sekolah, toko, bahkan perusahaan individu pun hampir semua memiliki website sebagai media promosi maupun informasi. Penelitian ini membahas tentang pengukuran mutu Website Akademi Komunitas Negeri (AKN) Pacitan menggunakan metode Webqual 4.0. Tujuan dari penelitian ini adalah untuk mengetahui variabel Webqual 4.0 yang mempengaruhi mutu Website AKN Pacitan dan memberikan saran untuk perbaikan mutu website dimasa yang akan datang agar sesuai dengan harapan pengguna. Penelitian ini dilakukan dengan menggunakan metode kuantitatif dengan cara penyebaran kuesioner, dengan jumlah 120 responden. Teknik analisis data dilakukan menggunakan teknik Structural Equation Model (SEM). Tools yang digunakan dalam penelitian ini yaitu SmartPLS 2.0 sebagai alat bantu PLS. Hasil penelitian ini menunjukkan bahwa diperoleh nilai $R$ Square untuk variabel User Satisfaction sebesar 0.677, yang artinya nilai tersebut mengindikasikan bahwa variabel User Satisfaction dapat dijelaskan oleh variabel Kegunaan (Usability), Kualitas Informasi (Information Quality), dan Kualitas Layanan (Service Interaction) sebesar $67.7 \%$, sedangkan sisanya yaitu sebesar $32.3 \%$ dipengaruhi oleh variabel lain yang tidak terdapat dalam model penelitian. Aspek-aspek ini dapat diperbaiki sesuai dengan rekomendasi yang diperoleh dari analisis data di dalam penelitian ini.
\end{abstract}

Kata Kunci:Website, Webqual 4.0, SEM, information Quality

\section{PENDAHULUAN}

Pada saat ini sudah banyak institusi pemerintahan yang memanfaatkan teknologi informasi, yaitu melalui website untuk meningkatkan layanan informasi dan kelancaran dalam menjalankan fungsinya sebagai layanan publik. Tanpa memiliki Teknologi Informasi yang cukup memadai, sulit bagi sebuah institusi pemerintahan untuk meningkatkan kualitas. Oleh karena itu perlu dilakukannya suatu investasi Teknologi Informasi untuk memperbaiki efektifitas kerja. Dalam hal ini, teknologi informasi telah menjadi kebutuhan pokok sebuah institusi untuk bertahan dan meraih keunggulan kompetitif. Namun sisi lain ada beberapa hal yang menjadi kendala yaitu investasi teknologi informasi membutuhkan biaya yang relatif besar. Kondisi ini membutuhkan perencanaan yang matang dalam mengimplementasikan teknologi informasi.
Selain itu, teknologi informasi juga membutuhkan tata kelola yang baik agar memperoleh hasil dan manfaat yang maksimal bagi suatu organsiasi. Namun banyak institusi pemerintahan yang mengalami kesulitan untuk memperkirakan manfaat investasi teknologi informasi dibandingkan nilai investasinya. Hal ini dikarenakan belum memiliki pedoman yang tepat dalam menganalisis manfaat investasi teknologi informasi.

Menurut Bell (2006), manajemen harus dapat bertanggung jawab akan setiap investasi yang dikeluarkan, termasuk investasi di bidang Teknologi Informasi yang tidak hanya meliputi peralatan, tetapi termasuk juga dengan sistem dan pemanfaatan sistem untuk kebutuhan bisnis. Tidak seperti jenis investasi lainnya, seperti gedung perkantoran atau peralatan, investasi

Teknologi Informasi tidak dapat dipandang sebagai sesuatu yang terus 
berkurang nilainya seiring dengan waktu, karena konteks nilai pada investasi TI tidak hanya dapat dipandang sebagai suatu nominal. Hal inilah yang menyebabkan banyak organisasi yang mengalami kesulitan untuk memperkirakan manfaat dari investasi TI tersebut dibandingkan nilai investasinya.

Dalam penelitian ini dilakukan pengukuran mutu website Akademi Komunitas Negeri Pacitan yang beralamat di http://www.aknpacitan.ac.id dengan menggunakan metode Webqual 4.0.

\section{METODE PENELITIAN}

Menurut teori Webqual, terdapat tiga dimensi yang mewakili kualitas suatu website, yaitu kegunaan (usability), kualitas informasi (information quality) dan interaksi layanan (service interaction) sebagaimana diilustrasikan dalam Gambar 1.

Persepsi pengguna tentang suatu sistem informasi yang baik adalah sebuah sistem dimana pengguna merasa puas dengan kualitas dari website. Kualitas ini termuat dalam tiga dimensi dari Webqual versi 4.0. Penelitian sebelumnya menyarankan bahwa dimensi Webqual dapat memprediksi kepuasan pengguna dan maksud pengguna dalam menggunakan kembali website (Loiacono, 2002). Berdasarkan model konseptual, penelitian ini memiliki hipotesis:

H1: Terdapat hubungan positif antara kegunaan dan kepuasan pengguna.

$\mathrm{H} 2$ : Terdapat hubungan positif antara kualitas informasi dan kepuasan pengguna.

H3: Terdapat hubungan positif antara interaksi kualitas layanan dan kepuasan.

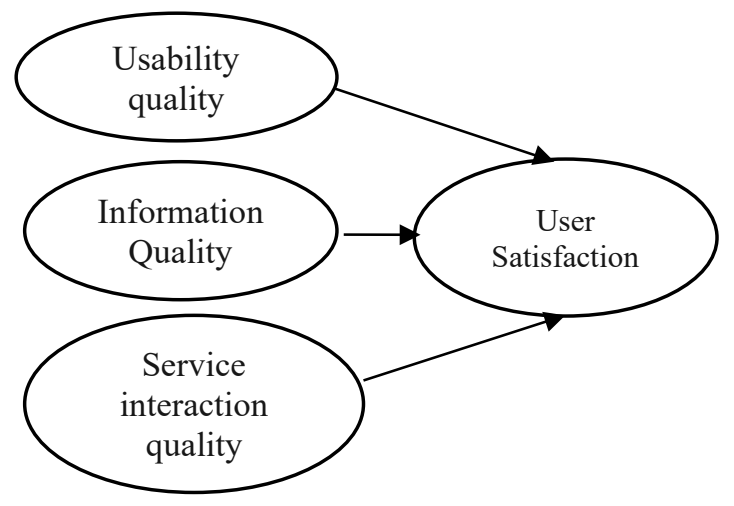

Gambar 1. Model Webqual 4.0 (Tarigan, 2009)

S kala pengukuran yang digunakan dalam penelitian ini adalah empat poin skala
Likert. Pengguna akan diminta menilai website untuk kualitas masing-masing menggunakan skala mulai dari 1 (sangat tidak setuju) hingga 4 (sangat setuju). Skala sengaja dibuat genap untuk menghindari kecenderungan responden yang besikap netral. Terlepas dari perdebatan apakah skala Likert memiliki jenis data ordinal ataukah interval, dalam penelitian ini diasumsikan data yang dperoleh adalah berjenis interval, sehingga dapat digunakan untuk statistika parametrik seperti analisis regresi linier berganda.

Penelitian dilaksanakan menggunakan teknik survey, dimana pengumpulan data primer dilakukan melalui penyebaran daftar pertanyaan (kuesioner). Sampel yang diambil sebanyak 120 responden. Ukuran sampel ini sesuai dengan penelitian yang dilakukan oleh Barnes dan Vidgen (2001) dalam mengukur kualitas website berita. Sampel dipilih secara purposive (judgment sampling) karena responden harus memiliki kriteria pernah menggunakan website Akademi Komunitas Negeri Pacitan sebelumnya.

\section{TINJAUAN PUSTAKA}

Webqual merupakan salah satu metode atau teknik pengukuran kualitas website berdasarkan persepsi pengguna akhir. Metode ini merupakan pengembangan dari SERVQUAL yang banyak digunakan sebelumnya pada pengukuran kualitas jasa. Webqual sudah mulai dikembangkan sejak tahun 1998 dan telah mengalami beberapa interaksi dalam penyusunan dimensi dan butir pertanyaannya. Webqual 4.0 disusun berdasarkan penelitian pada tiga area (dimensi) kualitas sebagaimana termuat dalam tabel 1 sampai tabel 3.:

Tabel 1. Dimensi Kemudahan Penggunaan (usability)

\begin{tabular}{|c|l|}
\hline No & \multicolumn{2}{|c|}{ Deskripsi Indikator } \\
\hline 1. & $\begin{array}{l}\text { Pengguna merasa mudah untuk } \\
\text { mempelajari pengoperasian website }\end{array}$ \\
\hline 2. & $\begin{array}{l}\text { Interaksi antara website dengan } \\
\text { pengguna jelas dan mudah dipahami }\end{array}$ \\
\hline 3. & $\begin{array}{l}\text { Pengguna merasa mudah untuk } \\
\text { bernavigasi dalam website }\end{array}$ \\
\hline 4. & $\begin{array}{l}\text { Pengguna merasa website mudah } \\
\text { untuk digunakan }\end{array}$ \\
\hline
\end{tabular}




\begin{tabular}{|c|l|}
\hline 5. & $\begin{array}{l}\text { Website memiliki tampilan yang } \\
\text { menarik }\end{array}$ \\
\hline 6. & Desain sesuai dengan jenis website \\
\hline 7. & Website mengandung kompetensi \\
\hline 8. & $\begin{array}{l}\text { Website menciptakan pengalaman } \\
\text { positif bagi pengguna }\end{array}$ \\
\hline
\end{tabular}

Sumber :

http://www.webqual.co.uk/instrument.htm

Tabel 2. Dimensi Kualitas informasi (information quality)

\begin{tabular}{|c|c|}
\hline No & Deskripsi Indikator \\
\hline 1. & Informasi yang disajikan akurat \\
\hline 2. & $\begin{array}{llll}\text { Informasi yang disajikan dapat } \\
\text { dipercaya }\end{array}$ \\
\hline 3. & $\begin{array}{l}\text { Informasi yang disajikan tepat waktu } \\
\text { dengan apa yang saya butuhkan }\end{array}$ \\
\hline 4. & $\begin{array}{l}\text { Informasi yang disajikan relevan } \\
\text { dengan apa yang saya inginkan }\end{array}$ \\
\hline 5. & $\begin{array}{l}\text { Informasi yang disediakan mudah } \\
\text { untuk dipahami }\end{array}$ \\
\hline 6. & Informasi yang disajikan sangat detail \\
\hline 7. & $\begin{array}{l}\text { Informasi yang disajikan dalam } \\
\text { format yang sesuai }\end{array}$ \\
\hline
\end{tabular}

Sumber :

http://www.webqual.co.uk/instrument.htm

Tabel 3. Dimensi Kualitas Interaksi

(interaction quality)

\begin{tabular}{|c|c|}
\hline No & Deskripsi Indikator \\
\hline 1. & Informasi yang disajikan akurat \\
\hline 2. & $\begin{array}{llll}\text { Informasi yang disajikan dapat } \\
\text { dipercaya }\end{array}$ \\
\hline 3. & $\begin{array}{l}\text { Informasi yang disajikan tepat waktu } \\
\text { dengan apa yang saya butuhkan }\end{array}$ \\
\hline 4. & $\begin{array}{l}\text { Informasi yang disajikan relevan } \\
\text { dengan apa yang saya inginkan }\end{array}$ \\
\hline 5. & $\begin{array}{l}\text { Informasi yang disediakan mudah } \\
\text { untuk dipahami }\end{array}$ \\
\hline 6. & Informasi yang disajikan sangat detail \\
\hline 7. & $\begin{array}{l}\text { Informasi yang disajikan } \\
\text { format yang sesuai }\end{array}$ \\
\hline
\end{tabular}

Sumber :

http://www.webqual.co.uk/instrument.htm

Versi pertama dari instrument Webqual (Webqual 1.0) dikembangkan sebagai bagian dari hasil lokakarya yang diselenggarakan dengan melibatkan para siswa yang diminta untuk mempertimbangkan kualitas website sekolah. Instrumen Webqual disaring melalui proses perbaikan secara iteratif dengan menggunakan kuesioner percobaan sebelum disebarkan untuk populasi yang lebih besar.

Duapuluh empat pertanyaan di dalam instrumen Webqual diuji dengan aplikasi dalam ruang lingkup website sekolah bisnis di Inggris. Analisis dari data yang dikumpulkan mendorong penghapusan atas satu item pertanyaan. Berdasarkan analisis reliabilitas, tersisa 23 pertanyaan yang kemudian dikelompokkan menjadi empat dimensi utama, yaitu kemudahan penggunaan, pengalaman, informasi, komunikasi dan integrasi (Barnes dan Vidgen, 2001).

Kualitas yang diidentifikasi dalam Webqual 1.0 membentuk titik awal untuk menilai kualitas informasi dari suatu website di Webqual 2.0. Namun demikian, dalam penerapan Webqual, pada website berjenis B2C (Business to Consumer) terlihat jelas bahwa perspektif interaksi kualitas tidak terwakili dengan baik dalam Webqual 1.0.

Terkait dengan kualitas pelayanan, terutama SERVQUAL, digunakan untuk meningkatkan aspek kualitas informasi dari Webqual dengan kualitas interaksi. Kualitas layanan umumnya didefinisikan dengan seberapa baik layanan yang disampaikan apakah sesuai dengan eskpektasi pelanggan. Pengembangan Webqual 2.0 memerlukan beberapa perubahan signifikan pada instrumen Webqual 1.0. Dalam rangka memperluas model untuk kualitas interaksi, Barnes dan Vidgen (2001) melakukan analisis terhadap instrument SERVQUAL dan membuat perbandingan rinci antara SERVQUAL dan Webqual 1.0. Tinjauan ini berhasil mengidentifikasi pertanyaan yang mubazir dan kemudian wilayah yang tumpang tindih dihapus, hasilnya sebagian besar pertanyaanpertanyaan kunci dalam SERVQUAL tidak sesuai dengan Webqual 2.0, jumlah instrumen dengan 22 pertanyaan tetap dipertahankan (Barnes dan Vidgen, 2001).

Webqual 1.0 mungkin kuat dalam hal kualitas informasi, namun kurang kuat dalam hal interaksi layanan. Demikian juga untuk Webqual 2.0 yang menekankan kualitas interaksi menghilangkan beberapa kualitas informasi dari Webqual 1.0. Kedua versi tersebut mengandung berbagai kualitas terkait dengan website sebagai artefak perangkat lunak. 
Dalam tinjauan yang dilakukan oleh Barnes dan Vidgen (2001) menemukan bahwa semua kualitas dapat dikategorikan menjadi tiga wilayah yang berbeda, yaitu kualitas website, kualitas informasi, dan kualitas interaksi pelayanan. Versi baru Webqual 3.0 telah diuji dalam domain lelang online (Barnes dan Vidgen, 2001).

Analisis dari hasil Webqual 3.0 membawa pada identifikasi tiga dimensi dari kualitas website, yaitu kegunaan, kualitas informasi, dan kualitas interaksi pelayanan. Kegunaan adalah kualitas yang berkaitan dengan desain website, misalnya penampilan, kemudahan penggunaan, navigasi dan tampilan yang disampaikan kepada pengguna. Kualitas informasi adalah kualitas isi website, kesesuaian informasi untuk keperluan pengguna seperti akurasi, format, dan relevansi. Kualitas interaksi layanan adalah kualitas interaksi layanan yang dialami oleh pengguna ketika mereka mempelajari lebih dalam suatu website, diwujudkan oleh kepercayaan dan empati, misalnya masalah transaksi dan keamanan informasi, pengiriman produk, personalisasi, dan komunikasi dengan pemilik website (Barnes dan Vidgen, 2001). Kegunaan telah menggantikan kualitas website di Webqual versi 4.0 karena menjaga penekanan pada pengguna dan persepsi mereka daripada perancang website. Istilah kegunaan juga mencerminkan dengan lebih baik tingkat abstraksi dua dimensi lain dari Webqual, yaitu interaksi layanan dan informasi. Kegunaan berkaitan dengan pragmatic tentang bagaimana pengguna melihat dan berinteraksi dengan website : apakah mudah bernavigasi? Apakah desain sesuai engan jenis website?

Penelitian yang mengukur kualitas website Akademi Komunitas Negeri Pacitan dengan metode Webqual, belum ada. Namun demikian, terdapat penelitian sejenis yang menggunakan metode Webqual, seperti yang dilakukan oleh Josua Tarigan (2008) yang mengukur sistem perpustakaan digital (e-library) dari Stock Exchange of Thailand (SET), begitu juga penelitian yang dilakukan oleh Handini (2009) yang mengukur mutu layanan perpustakaan perguruan tinggi.

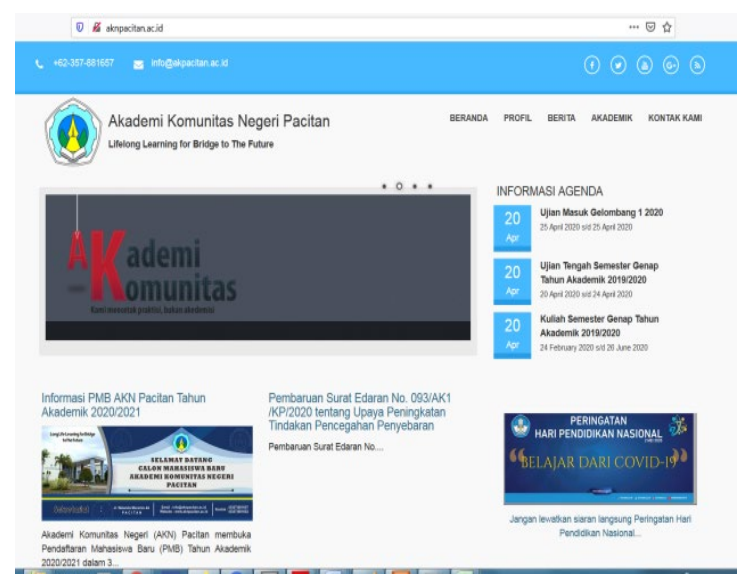

Gambar 2. Tampilan Website Akademi Komunitas Negeri Pacitan, diakses tanggal

19 April 2020

\section{HASIL DAN PEMBAHASAN}

Dari total kuesioner yang diperoleh, yaitu sebanyak 120 responden, dilakukan analisis data dengan menggunakan software SmartPLS 2.0/ Langkah awal yang dilakukan adalah dengan melakukan uji validitas dan reliabilitas dari pertanyaan-pertanyaan dalam kuesioner

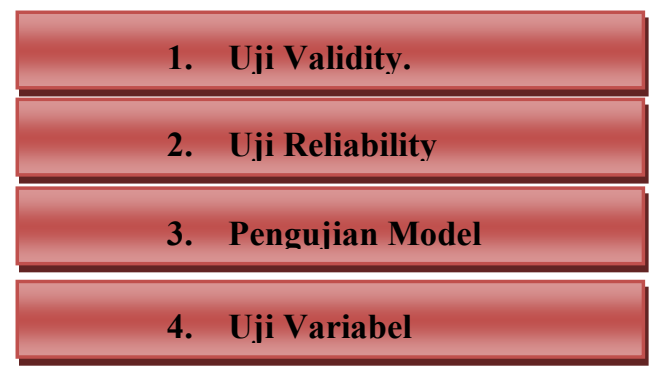

Gambar 3. Tahapan penelitian

Pengujian validitas dan reliabilitas adalah proses menguji butir-butir pertanyaan yang ada dalam sebuah kuesioner, apakah isi butir pertanyaan sudah valid dan reliabel. Jika butir-butir sudah valid dan reliabel, berarti butir-butir tersebut sudah bisa digunakan untuk mengukur faktornya. Langkah selanjutnya adalah menguji apakah faktorfaktor sudah valid untuk mengukur konstruk yang ada. Dalam pengujian butir tersebut, bisa saja ada butir-butir yang ternyata tidak valid dan reliabel, sehingga harus dibuang atau diganti dengan pertanyaan yang lain (Santoso, 2006). Uji validitas dilakukan dengan melihat masing-masing konstruk dalam model penelitian lihat Gambar 4. 


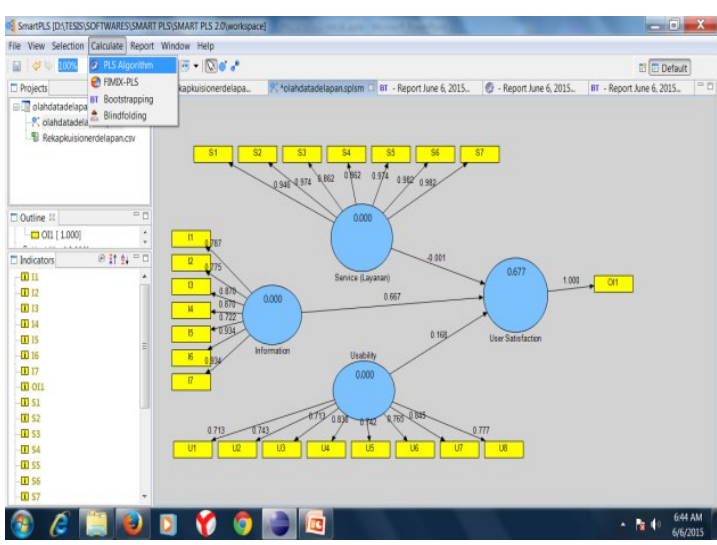

Gambar 4. Model Penelitian dalam SmartPLS 2.0

Menguji dari masing-masing konstruk dengan melihat convergent validity dari masing-masing indikator konstruk. Suatu indikator dikatakan reliable yang baik jika nilainya lebih besar dari 0.70 (Ghozali, 2008). Jika masa ada nilai Factor loading yang nilainya di bawah 0.70 kita drop dari analisis atau kita buang dari jalur model karena memiliki nilai convergent validity rendah, untuk itu nilai loading harus memenuhi syarat validitas lebih besar dari 0.70 (Ghozali, 2008). Suatu Konstruk dikatakan valid dan Reliabel jika mempunyai nilai AVE dan Communality diatas 0.50 dan Composite Reliability diatas 0.70 (Ghozali, 2008).

Tabel 4. AVE Tiap Variabel

\begin{tabular}{|c|c|}
\hline & AVE \\
\hline Information & 0.714315 \\
\hline Service (Layanan) & 0.886887 \\
\hline Usability & 0.588659 \\
\hline User Satisfaction & 1.000000 \\
\hline
\end{tabular}

Tabel 5. Communality Tiap Variabel

\begin{tabular}{|c|c|}
\hline & communality \\
\hline Information & 0.714315 \\
\hline Service (Layanan) & 0.886887 \\
\hline Usability & 0.588659 \\
\hline User Satisfaction & 1.000000 \\
\hline
\end{tabular}

Tabel 6. Composite Reliability tiap Variabel

\begin{tabular}{|c|c|}
\hline & $\begin{array}{c}\text { Composite } \\
\text { Reliability }\end{array}$ \\
\hline Information & 0.945537 \\
\hline Service (Layanan) & 0.982055 \\
\hline Usability & 0.919399 \\
\hline User Satisfaction & 1.000000 \\
\hline
\end{tabular}

Artinya variabel yang dipakai untuk penelitian ini sudah valid dan Reliabel atau telah memenuhi Convergent Validity dan Reliability. Bisa juga dengan menganalisa Tabel. 7 outer loading.

Tabel 7. Outer Loading

\begin{tabular}{|c|c|c|c|c|}
\hline & Information & $\begin{array}{l}\text { Service } \\
\text { (Layzanan) }\end{array}$ & Usabututy & User Satistaction \\
\hline $\mathrm{I1}$ & 0.785917 & & & \\
\hline 12 & 0.775406 & & & \\
\hline 13 & 0.870009 & & & \\
\hline 14 & 0.870009 & & & \\
\hline 15 & 0.721950 & & & \\
\hline 16 & 0.934023 & & & \\
\hline 17 & 0.930023 & & & \\
\hline or1 & & & & 1.000000 \\
\hline 51 & & 0.505438 & & \\
\hline 52 & & 0.974130 & & \\
\hline 53 & & 0.862335 & & \\
\hline 54 & & 0.862335 & & \\
\hline 55 & & 0.974130 & & \\
\hline 56 & & 0.981547 & & \\
\hline 57 & & 0.981547 & & \\
\hline $\mathrm{u}_{1}$ & & & 0.712790 & \\
\hline $\mathrm{Uz}$ & & & 0.742847 & \\
\hline u3 & & & 0.712790 & \\
\hline 44 & & & 0.830101 & \\
\hline us & & & 0.741570 & \\
\hline 46 & & & 0.756955 & \\
\hline u7 & & & 0.844589 & \\
\hline 48 & & & 0.777052 & \\
\hline
\end{tabular}

Hasil dalam penelitian uji validitas konvergen ini telah memenuhi validitas konvergen, karena semua indikator memiliki skor loading lebih besar dari 0.70 (Ghozali, 2008)

Menurut Hair dalam Latan \& Ghozali (2012), suatu model dikatakan kuat jika nilai $\mathrm{R}$ Square 0.75 . model moderat jika nilai $\mathrm{R}$ Square 0.50 , dan model lemah jika nilai $\mathrm{R}$ Square 0.25. Uji R Square merupakan uji goodness-fit model

Tabel.8. R Square

\begin{tabular}{|c|c|}
\hline & R Square \\
\hline Information & \\
\hline Service (Layanan) & \\
\hline Usability & \\
\hline User Satisfaction & 0.676683 \\
\hline
\end{tabular}




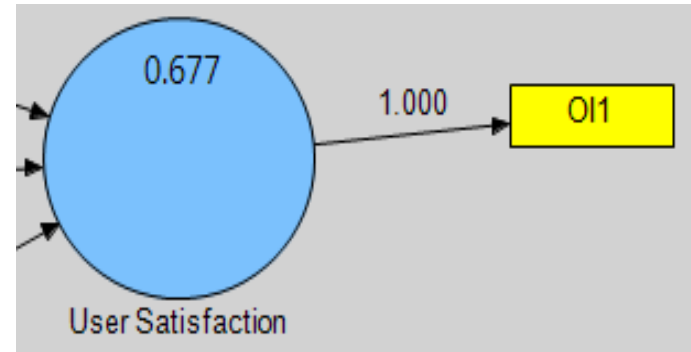

Gambar 5. Goodness Fit Model

Maka hasil Gambar.5 tersebut diperoleh nilai $R$ Square dan Goodness fit model sebesar 0,677, yang artinya nilai tersebut mengindikasikan bahwa user satisfaction dapat dijelaskan oleh variabel konstruk ( Usability, Informaton Quality dan Service Interaction ) sebesar 67,7 \% sedangkan sisanya yaitu sebesar 32,3\% dipengaruhi oleh variabel lain yang tidak terdapat dalam model peneltian ini.

Untuk mendapatkan uji hipotesis dan nilai path coefficient maka dilakukan pengujian dengan fungsi Bootstrapping lihat pada Gambar. 6

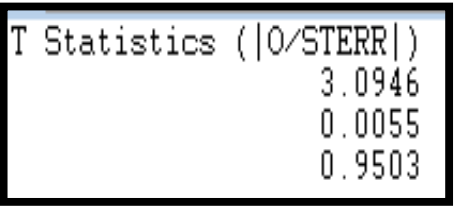

Gambar 6. T- Statistic

Berikut penjelasan lebih detail bisa dilihat pada Tabel. 9.

Tabel 9. T-Statistics

\begin{tabular}{|l|l|l|}
\hline \multicolumn{1}{|c|}{$\begin{array}{c}\text { Hubungan } \\
\text { Variabel }\end{array}$} & T. Tabel & T. Hitung \\
\hline $\begin{array}{l}\text { Usability - User } \\
\text { Satisfaction }\end{array}$ & 1,65787 & 0,9503 \\
\hline $\begin{array}{l}\text { Information - } \\
\text { User Satisfaction }\end{array}$ & 1,65787 & 3,0946 \\
\hline $\begin{array}{l}\text { Services - User } \\
\text { Satisfaction }\end{array}$ & 1,65787 & 0,0055 \\
\hline
\end{tabular}

Berdasarkan hasil analisis data dengan menggunakan Smart PLS 2.0 M3 melalui fungsi bootstrapping di atas diperoleh beberapa hubungan antara variabel yang berpengaruh terhadap website Akademi Komunitas Negeri Pacitan. Menurut Ghozali
(2008), kriteria signifikan adalah $\mathrm{t}$ hitung lebih besar daripada t tabel pada alpha 5\%, 1,65787. Sehingga variabel yang mempunyai hubungan yang signifikan ditunjukkan dalam tabel 4. Tabel di atas menunjukkan hubungan variabel yang signifikan (ditandai dengan warna biru), karena $\mathrm{t}$ hitung lebih besar daripada t tabel pada alpha 5\%, yaitu lebih besar dari 1,65787.

Maka dari hasil penelitian ini berdasarkan nilai di atas maka Information User Satisfaction diterima dan bernilai positif karena $\mathrm{t}$ hitung lebih besar dari $\mathrm{t}$ tabel. Sedangkan Services - User Satisfaction dan Usability - User Satisfaction ditolak karena $\mathrm{t}$ hitung lebih kecil dari t tabel.

\section{KESIMPULAN DAN SARAN}

\section{a. Kesimpulan}

Berdasarkan hasil pengumpulan dan analisis data dalam penelitian ini, maka dapat diambil kesimpulan bahwa dari sebanyak 23 butir pertanyaan yang membentuk dimensi dimensi dari Webqual, semua butir pertanyaan dianggap valid, sedangkan dari 3 dimensi Webqual 4.0, hanya dimensi kualitas informasi (Informatio Quality) yang dinilai berpengaruh positif terhadap user satisfaction atau berpengaruh pada mutu website, sedangkan dimensi Kegunaan (Usability) dan dimensi Kualitas Interaksi (Interaction Quality) dinilai tidak berpengaruh tehadap user satisfaction website atau mutu website. Sehingga disimpulkan bahwa variabel yang mempengaruhi mutu website AKN Pacitan adalah variabel Kualitas Informasi (Information Quality), hal ini bisa menjadi catatan bagi pengelola website AKN Pacitan untuk terus meningkatkan mutu dari website apalagi website ini sebagai media informasi digital bagi kampus AKN Pacitan kepada mahasiswa.

\section{b. Saran}

Dengan dilakukannya penelitian ini maka diperoleh gambaran bahwa terdapat variabel yang mempengaruhi mutu website AKN Pacitan, yaitu variabel Kualitas Informasi (Information Quality).

Penelitian ini belum mengukur semua variabel secara rinci/detail sebagai pengaruh dari mutu website ini dikarenakan keterbatasan waktu dan biaya, sehingga memerlukan penelitian dan pengkajian lebih 
lanjut. Terlepas dari kontribusi yang diberikan penelitian ini, dalam rangka penyempurnaan lebih lanjut, khususnya terkait dengan metodologi penelitian, peneliti bermaksud menyampaikan beberapa saran sebagai berikut: Penelitian ini mengambil responden dengan teknik Purposive Sampling dari mahasiswa lintas prodi yang ada di kampus, dengan asumsi mereka sudah pernah mengakses Website Akademi Komunitas Negeri Pacitan. Dimensi-dimensi yang ada pada Webqual hanyalah salah satu metode dalam mengukur kualitas suatu website. Dalam konteks penelitian lebih lanjut, mungkin perlu juga mencoba dimensi lain seperti yang diusulkan oleh Hair (2009) meliputi kegunaan, presentasi, konten, komunikasi, dampak konsumen, dan kepercayaan.

\section{REFERENSI}

Asad Ahmad \& Mohammed Naved Khan .(2017). Developing a Website Service Quality Scale: A Confirmatory Factor Analytic Approach, Journal of Internet Commerce, 16:1, 104-126, DOI: 10.1080/15332861.2017.1283927

Barnes S, idgen, R.(2001). Assessing the Quality of Auction Websites. $34^{\text {th }}$ Hawaii International Conference on System Sciences.

Budihartanti, Cahyani; Rusiyati, Sri; Badrul, Mohammad. Evaluasi Kualitas Website BPJS Kesehatan Menggunakan Metode Webqual dan Importance Performance Analysis. Journal of Information System, Applied, Management, Accounting and Research, [S.1.], V. 3, N. 4, p. 63-69, Nov. 2019. ISSN 25988719

E.E. Barus, Suprapto, A.D Herlambang.(2018).Analisis Kualitas Website Tribunnews.com Menggunakan Metode Webqual dan Importance Performance Analysis Jurnal Pengembangan Teknologi Informasi dan Ilmu Komputer, 2, 4, , pp. 1483-1491.

Hair, N.(2009). A Study of Website Quality Components. Rochester Institute of Technology.

Handini.(2009). Pengukuran Mutu Layanan Perpustakaan Perguruan Tinggi dengan Menggunakan Metode Webqual (Studi Kasus : Web Library Perguruan Tinggi
Swasta dan Perguruan Tinggi Negeri). Jakarta : Universitas Gunadarma.

Rahayu, Luci Kanti; Mustika, Wida Prima; Wahyudi, Wahid Fajar. Webqual 4.0 Untuk Evaluasi Kualitas Layanan Website E-Commerce Alzafa.Com Terhadap Keputusan Pembelian Online. Journal of information system, applied, management, accounting and research, [s.1.], v. 2, n. 1, p. 47-54, apr. 2018. Issn 2598-8719.

Tarigan, J.(2008). User Satisfaction using Webqual Instrument : A Research on Stock Exchange of Thailand (SET). Jurnal Akuntansi dan Keuangan. Vol. 10 No. $1: 34-47$. 